\section{Análisis pragmático de los actos de habla irónicos y humorísticos en comentarios publicados en las páginas de Facebook de cuatro noticieros costarricenses}

\author{
A pragmatic analysis of ironic and humoristic \\ speech acts in the comments published on the \\ Facebook pages of four Costa Rican newspapers
}

\author{
Mariana Cortés Kandler (D), Yordan Arroyo Carvajal \\ ${ }^{1}$ Universidad de Ottawa, Canadá / Universidad de Costa Rica, Costa Rica \\ mcort012@uottawa.ca \\ ${ }^{2}$ Universidad de Salamanca, España / Universidad de Costa Rica, Costa Rica \\ yordan.arroyo@ucr.ac.cr
}

ACCESO ABIERTO / OPEN ACCESS

Cita: Cortés Kandler, Mariana y Arroyo Carvajal, Yordan (2021). Análisis pragmático de los actos de habla irónicos y humorísticos en comentarios publicados en las páginas de Facebook de cuatro noticieros costarricenses. Textos en Proceso, 7(1), pp. 76-99.

https://doi.org/10.17710/tep.2021.7. 1.5cortes_arroyo

Editoras: Esperanza Alcaide Lara (Universidad de Sevilla) y Ana Pano Alamán (Università di Bologna)

Recibido: 19/03/2021

Aceptado: 20/07/2021

Conflicto de intereses: Los autores han declarado que no poseen conflicto de intereses.

Copyright: @ Mariana Cortés Kandler y Yordan Arroyo Carvajal. Esta obra está bajo licencia Creative Commons Reconocimiento 4.0

\section{Resumen}

En este artículo se analizan las funciones de los actos de habla irónicos y humorísticos, desde el punto de vista de la pragmática, en 29 comentarios, inmersos en 16 casos recogidos de las páginas de Facebook de cuatro noticieros costarricenses: Diario Extra, La Nación, CRHoy y Semanario Universidad. Se descubrió que entre la ironía y el humor prevalece la ironía, recurso cuya función principal en la muestra es transmitir el descontento social respecto a la situación política vivida en noviembre de 2019 en Costa Rica. También, se hallaron abundantes casos de recursos no verbales, principalmente emojis, que les permitieron a los usuarios reforzar sus actos de habla, o bien multiplicar las posibilidades de análisis pragmático. Este estudio se suma a otras investigaciones que examinan la ironía y el humor en las redes sociales, y abre horizontes a futuras investigaciones tanto en Costa Rica como en el mundo dentro de este campo, donde los estudios pragmáticos sobre análisis del discurso mediado por computadoras, hasta hoy, son escasos.

Palabras clave: discurso mediado por computadoras, pragmática, actos de habla, crítica social, identidades cibernéticas.

\section{Abstract \\ This paper analizes the function of the speech acts of irony and humor, from the perspective of pragmatics, in 29 comments from 16 posts or chains of posts, published in the Facebook pages of four Costa Rican newspapers: Diario Extra, La Nación, CRHoy, and Semanario Universidad. Irony was found to be more common}


than humor, mainly with the function of communicating social discontent towards the political situation during November 2019 in Costa Rica. In addition, there were numerous non-verbal resources used in the simple, mainly emojis, which allow users to reinforce their speech acts, or even offer alternative interpretations. This paper joins other projects that examine irony and humor in social media, and it offers new possibilities of research not only in Costa Rica, but also abroad, in the field of computer-mediated speech analysis, where studies are still scarce.

Keywords: computer-mediated speech analysis, pragmatics, speech acts, social cristicism, cybernetic identities.

\section{Introducción}

Con base en Ridao (2020), las redes sociales y los instrumentos tecnológicos han llegado a dominar la comunicación en un nivel antes inimaginable. Cada vez hay más usuarios utilizando la red social Facebook como un medio de simple expresión o como un espacio para abrir o generar discusiones sobre diferentes molestias en los usuarios de un determinado país. En especial, para los objetivos de este trabajo, interesa analizar las funciones de los actos de habla ${ }^{1}$ que se utilizan en este tipo de discursos, principalmente políticos, los cuales están proliferando a una velocidad vertiginosa en Costa Rica, y probablemente en el mundo. Sin embargo, la investigación desde una metodología pragmática parece todavía no seguirle el ritmo. Por ende, este estudio pretende contribuir al conocimiento de ese discurso mediado por computadoras, que actualmente es uno de los principales en la humanidad.

Para Cabo Isasi y García Juanatey (2016), estudiar los comentarios publicados por los usuarios en Facebook es conocer rasgos no solo sobre su identidad cibernética, sino sobre la valoración del estado económico o político de un país. A nivel costarricense, no se encontraron estudios pragmáticos que analicen los actos de habla irónicos y humorísticos en las redes sociales. Hasta el momento, la mayoría de las investigaciones en esta área han sido realizadas en España, por ejemplo, Vigara, Attardo y el personal académico de la Universidad de Alicante que conforman el Grupo de Investigación sobre Ironía y Humor en Español (GRIALE).

Por esta razón, en este estudio se lleva a cabo un análisis pragmático sobre las funciones que poseen dos actos de habla: la ironía y el humor en 29 comentarios, inmersos en 16 casos recogidos de las páginas de Facebook de cuatro noticieros costarricenses (Diario Extra, CRHoy, La Nación y Semanario Universidad), con un considerable público receptor. Se escogieron estos actos de habla porque guardan consigo procesos de metacomprensión ${ }^{2}$.

Por otro lado, respecto a la red social "Facebook", para Sal Paz (2016) es un medio donde surge un género dialógico (reflejo de gran parte de una sociedad específica) que permite la polifonía o el refuerzo de determinados actos de habla

\footnotetext{
${ }^{1}$ Para Susana Ridao (2020), las teorías de los actos de habla en el siglo XX supusieron el nacimiento de la pragmática.

${ }^{2}$ Denominación utilizada por Villegas (2007).
} 
mediante secuencias argumentativas. Esta secuencia de comentarios tiende a reforzar las intenciones discursivas que se esconden detrás de los comentarios en Facebook, cuyas funciones se analizarán en este trabajo. Para ello, se escogieron noticias relacionadas con temas políticos, puesto que, durante el proceso de estudio, noviembre de 2019, se comprobó la amplia interacción entre los usuarios con respecto a estos temas.

Del total de la muestra, se seleccionaron los actos de habla irónicos y humorísticos que permitieran análisis pragmáticos más detallados, y que estuvieran relacionados con la situación política que se vivía en Costa Rica durante 2019, poco antes del comienzo de la pandemia de COVID-19, situación que exacerbó la discordia política y administrativa del país, lo cual podría ser objeto de nuevas investigaciones desde esta óptica. Se encontró abundante material que refleja un pueblo molesto con su gobierno actual.

Para el análisis de los actos de habla, se muestran los rasgos discursivos más comunes de la secuencia textual que Cautín-Epifani (2015) denomina "discurso mediado por computadoras" 3 (DMC). Se consideran además los emojis, que a menudo provocan un reforzamiento en el acto de habla irónico (Sampietro, 2016) ${ }^{4}$. A fin de describir la estructura de estos actos de habla (ironía y humor), se identifica, en un primer paso, si consisten en ironía o en humor. Luego, se identificaron los recursos verbales y no verbales utilizados en cada acto de habla. Por último, se ofrece una posible interpretación de la intención comunicativa según el contexto político en el que se realizó, con el fin de proponer una lectura de esa sociedad a partir de la muestra conformada por sus ciudadanos. El análisis de los comentarios indica que, en el contexto de un país en crisis en noviembre de 2019, existían usuarios molestos con la actual administración del gobierno del Partido Acción Ciudadana (PAC).

\subsection{Aproximaciones pragmáticas al discurso mediado por computadoras}

Las investigaciones con enfoque pragmático sobre el discurso mediado por computadoras son todavía escasas, particularmente a nivel costarricense. En este apartado se exponen algunos estudios que resultaron relevantes para este trabajo, así como los conceptos clave que se emplearán para el análisis: ironía, humor y recursos no verbales en redes sociales.

En lo que corresponde a la línea de investigación de este trabajo, en Costa Rica no se encontró ningún estudio de análisis pragmático de discursos mediados por computadoras; sin embargo, González (2020) y Siles et al (2018) se aproximan a la temática, pues ambos utilizan material recopilado de noticieros en Facebook

\footnotetext{
${ }^{3}$ Sal Paz (2016) habla de "discurso mediado por ordenador" para referir que no interesa el objeto de acceso (teléfono o tableta), puesto que lo que importa es la función del mensaje emitido por el interlocutor.

${ }^{4}$ A los emojis se les deben sumar los signos de pregunta, los gifs sobre memes, las risas y las secuencias discursivas, todos ellos clasificadas por Cautín-Epifani (2015), quien los denomina "recursos no verbales". La diferencia entre emoji y emoticono es que el primero es la imagen gráfica como tal (:), mientras el segundo es construido (:c).
} 
como una posibilidad de acercarse a las identidades tanto de sus usuarios como de la sociedad donde viven, en relación con temas políticos. A nivel internacional, Yus (2014) propone el concepto de identidades cibernéticas para referirse, desde la red social misma, a la construcción de una identidad en el usuario. ${ }^{5}$

Respecto al uso de estos discursos en Facebook, según Vargas (2016) tras citar a Bajtín (1995), los usuarios suelen utilizarlos como un espacio de catarsis de sus sentimientos, ideas, emociones, etc., haciendo uso de la ironía y el humor para carnavalizar el discurso de las élites políticas. Gran parte de estos estudios coinciden en indicar la escasez de estudios al respecto, $y$, por ende, invitan a nuevo personal investigador a sumarse a esta tarea.

\subsection{Ironía y humor}

Una vez aclarado el propósito de los estudios sobre discurso escrito en redes sociales, cabe referirse a los conceptos de humor e ironía, componentes principales de este artículo.

\subsubsection{Ironía}

El grupo GRIALE de la Universidad de Alicante ha desarrollado dos grandes proyectos sobre el análisis de la ironía: Análisis pragmático de la ironía verbal. Tipología y aplicaciones a la enseñanza del español como lengua extranjera (20042007) y Aplicaciones a la clase de español como lengua extranjera de la ironía y el humor (2008-2011). No obstante, Ruiz Gurillo (2014) menciona que la mayoría de los trabajos sobre ironía han sido realizados en el campo de literatura, con escaso tratamiento pragmático en relación con el discurso mediado por computadoras.

Para su análisis, Ruiz Gurillo (2010) propone un análisis pragmático a partir de los principios de cantidad, de manera y de informatividad. ${ }^{6}$ Con respecto a los indicadores de la ironía, Grupo GRIALE los clasifica en ámbitos de lo no lingüístico y de lo lingüístico. Dentro de lo no lingüístico se encuentran los aspectos kinésicos, paralingüísticos y acústico-melódicos; y dentro de lo lingüístico, la puntuación, los cambios tipográficos, las variaciones lingüísticas, las palabras de alerta, las unidades fraseológicas, la formación de palabras y las figuras retóricas.

Por último, Caro, Camargo y Uribe (2018) indican que, actualmente, el estudio de la ironía ha superado su visión única y tradicional de antífrasis (ironía prototípica, Ruiz Gurillo 2010). ${ }^{7}$ Este recurso puede emplearse con una carga positiva, negativa o neutral, y tiene indicadores lingüísticos y no lingüísticos, como memes, emojis, risas, emoticones, signos de puntuación y memes. ${ }^{8}$

\footnotetext{
${ }^{5}$ La ciberpragmática remite al estudio del lenguaje mediado por computadoras. Según Lozarez, Verd, Martí y López (2002), a partir de los 80, la lingüística comenzó a tener interés en este tipo de discurso.

${ }^{6}$ La polisemia es el indicador más utilizado en la ironía no prototípica. Es decir, cosas diferentes, pero no contrarias. Dice algo diferente a lo que expresan las palabras.

${ }^{7}$ Cuando dice cosas diferentes, es decir, no necesariamente contrarias, según Ruiz Gurillo (2010) es ironía no prototípica.

${ }^{8}$ Desde la visión de Ruiz Gurillo (2010): "Entendemos por marcas aquellos elementos que ayudan a la interpretación irónica. Por su parte, los indicadores son estructuras de por sí irónicas. Tanto las marcas como los indicadores pueden relacionarse con inferencias de carácter generalizado que, sin
} 
Para Caro, Camargo y Uribe (2018), la agresividad que conlleva un mensaje no es inherente a la ironía, sino una potencialidad de esta, ya que pasa por distintos niveles de interpretación y no es exclusivamente negativa. Puede servir, además, como recurso de creatividad y de construcción de ideas abstractas donde el receptor (presuposición) y el contexto de ambos (emisor-receptor) tiene un papel vital. ${ }^{9}$

Asimismo, al atender a la intención del mensaje ironizado se podrá descubrir su significado. El público lector tiene un papel importante de interpretación. Además, cuando una ironía se entiende, es posible, a modo de respuesta, plantear nuevas ironías. ${ }^{10}$ En el acto de ironía, el emisor presenta al lector una serie de indicadores, descritos por Muecke (1978) y Schoentjes (2003), citados por Alvarado Ortega $(2006)^{11}$, los cuales serán el objeto de estudio en este trabajo.

\subsubsection{Humor}

Vigara Tauste, ${ }^{12}$ una de las grandes estudiosas del humor y referente indiscutible de la Universidad Complutense de Madrid, explica que el humor puede verse desde diferentes directrices. Entre ellas, se encuentra el humor como un acto pragmático en constante acción, cuyo objetivo es provocar risa en sus receptores por medio de catarsis o emociones; es decir, puede ser un acto positivo, propiamente cómico o risible. Para términos de esta investigación, interesará más otra de sus concepciones: el humor como una acción cuyo propósito social es reírse, ya no por goce o placer, sino a modo de protesta contra quienes intentan romper los derechos y valores universales de la humanidad. De este modo, se convierte en una herramienta de resistencia cuyo acto de placer es lograr el cuestionamiento y, posteriormente, la ruptura de un conocimiento falso o que le incomoda a quien ejerce la risa, ya sea oral o escrita.

Al respecto, Rodríguez (2020) propone que el humor puede funcionar como crítica social, lo cual permite un acercamiento a ciertos sectores del pueblo. Es decir, debajo del humor se puede esconder una pincelada de crítica dirigida a cierto sector social; la pragmática se encarga de descifrar estas intenciones ocultas en el lenguaje. ${ }^{13}$ Justamente, tal cual apunta la autora, el uso de lo humorístico como manifestación contestataria contra vicios económicos, sociales o políticos ha crecido cada vez más con la entrada del siglo XXI:

\footnotetext{
negar la condición de inferencia particularizada de la ironía, ofrecen desde el punto de vista teórico una conexión con los tipos de enunciado en los que se produce" (p. 2). Por su lado, están los marcadores que guían el acto irónico o sirven como refuerzo, entre ellos están sufijos y conectores de contradicción como "pero", que sirve como contraste entre dos argumentos. También, marcadores de evidencia como "claro", para permitir una ironía continuada.

${ }^{9}$ Según Ruiz (2010) la ironía, entre sus muchas significaciones, depende del contexto donde se produce.

${ }^{10}$ A ello, Sal Paz (2016) lo llama secuencia argumentativa.

${ }^{11}$ En términos más precisos, según Ruiz (2010) "La ironía se puede explicar como violación de las máximas (Grice), como eco (Sperber y Wilson), como fingimiento (Clark y Gerrig) o como entorno irónico (Utsumi), entre otros" (p. 8), por ejemplo, como "hecho pragmático localizado en las expresiones verbales y no verbales utilizadas" (p. 8).

${ }^{12}$ Citada en Rodríguez (2020).

13 "Siguiendo lo establecido en Ruiz Gurillo (2006), el humor es un hecho pragmático que se explica a la luz de la pragmática, entendida principalmente como perspectiva” (Ruiz Gurillo, 2019, p. 184).
} 
En años más recientes, diversos personajes utilizan plataformas digitales para difundir noticias y análisis con un toque abiertamente cómico y muchas veces irónico. La crítica desde el humor permite, así, mirar dos veces una realidad intencionalmente disimulada, una situación que no se tolera, un absurdo que deja de ser visible, víctima de la monotonía; produciendo de esta manera humor sobre una situación cotidiana y ofreciendo al receptor una mirada crítica sobre la manera de comportarse dentro de la sociedad (p. 4).

Detrás del humor como recurso pragmático, en el acto de habla existe episteme. Una risa podría ser simplemente una acción liberadora de las emociones del ser, sin ningún fin crítico de fondo, o bien, encadenar en sí misma una molestia que apunta hacia un mensaje crítico que se mantiene oculto en el lenguaje oral o en el escrito, ${ }^{14}$ hecho que Casado (2018) denomina "hecho performativo de resistencia política".

Ruiz Gurillo (2014) presenta una propuesta para el análisis del humor desde la pragmática (a partir de fuentes como Levinson 2000), similar a Caro, Camargo y Uribe (2018) y el grupo GRIALE de la Universidad de Alicante. Según la autora, el acto humorístico se genera a partir de "la infracción de los principios pragmáticos que gobiernan la comunicación" (p. 150). Existe una distanciamiento de los códigos de seriedad que conforman la comunicación tradicional, lo cual rompe con los principios pragmáticos de cantidad, manera e informatividad. ${ }^{15}$ Más específicamente, para el presente trabajo interesa ubicar "marcas" o "indicadores" propios de este recurso, tales como la entonación y las pausas, o indicadores con base semántica como la polisemia, la homonimia, la antonimia, la paronimia o los pseudoabarcadores (p. 152) y la fraseología, la variación y la creación léxica (p. 156)..$^{16}$

\subsection{Recursos no verbales en redes sociales (emojis ${ }^{17}$ y reacciones $)^{18}$}

Sampietro (2016) indica que los emojis sirven como recurso para fortalecer un acto irónico o humorístico cuando se genera antífrasis. Por esta razón, Dresner y Herring (2010), citados por Sampietro (2016), argumentan que los emojis sirven para "indicar la fuerza ilocutiva del enunciado" (p. 228). Además, también "ayudan a hacer explícitas afirmaciones irónicas, sarcásticas, bromas o humor" (ídem). Se expone el siguiente ejemplo: "(39) [P30_40_1, turno 30] 1. Patricia: Te mato () -), (p. 228). Sampietro (2016) comenta que el uso del emoji "sonriente" junto al "te mato" (p. 228) remite a una intimidación irónica o ficticia. Cabe agregar que, a lo largo de su tesis cita otras referencias para denotar la función que poseen los

\footnotetext{
${ }^{14}$ En el lenguaje escrito se valorará la expresión "ja, ja, ja [...]" y los emojis que remiten a actos risibles.

${ }^{15}$ Según Ruiz Gurillo (2014) en este acto de habla, contrario al de la ironía, no se transgrede tanto el principio de informatividad, sino el de cantidad y el de manera.

${ }^{16}$ Es importante recordar que todo ello remite a la incongruencia y ambigüedad del mensaje.

${ }^{17}$ En inglés se les conoce como "emoji" o "stickers" (Sampietro, 2016, p. 43); surgen de los emoticonos.

${ }^{18}$ El estudio más completo sobre los emoticonos es la tesis doctoral de Sampietro (2016): Emoticonos y emojis: Análisis de su historia, difusión y uso en la comunicación digital actual.
} 
emojis en lo concerniente a refuerzo de cumplidos, pues "los aspectos sociales, pragmáticos, técnicos e interaccionales están muy ligados” (p. 236).

\section{Metodología}

\subsection{Fuentes de datos}

Para la recolección de los datos, se examinaron 29 comentarios en cuatro periódicos costarricenses publicados en la red social Facebook: Diario Extra, CRHoy, La Nación y Semanario Universidad. ${ }^{19}$ Enseguida, se muestra una breve información de cada uno, obtenida de las respectivas páginas en Facebook:

- Diario Extra: Hasta el 22 de agosto de 2020, cuenta con 1050781 seguidores en Facebook. Se caracteriza por ser un noticiero que publica 10 o más noticias diarias en la red. Sin embargo, para este trabajo, las que mostraron mayor reacción en noviembre de 2019 fueron solo dos. Entre sus seguidores, se observan usuarios con perfiles sociales de toda índole en relación con la calidad de la ortografía y la redacción. Según la página de Diario Extra y su plataforma en Facebook, este periódico es catalogado como el de mayor venta en Costa Rica, con gran cantidad de seguidores, a pesar de que sus noticias se caracterizan por el amarillismo (Sánchez Molina, 2002). A través de la recolección de los datos para este trabajo, se comprobó la redacción de comentarios informales en la página de este noticiero.

- La Nación: Hasta el 22 de agosto de 2020, cuenta con 836004 seguidores en Facebook, es decir, poseen menos seguidores que Diario Extra (1.050.781). Como característica, muchas de sus noticias se encuentran restringidas debido a que cobran por su acceso. Además, no publican la misma cantidad de noticias que Diario Extra. Comparten entre una y dos noticias por día, e incluso indican que se caracterizan por seleccionar solo las mejores notas. Posee poca participación en cuanto a comentarios, tanto en las noticias utilizadas para este artículo como de manera general. En los comentarios extraídos para el análisis, se nota la presencia de usuarios que utilizan un lenguaje un poco más culto en comparación con los comentarios observados en Diario Extra y CRHoy.

- CRHoy: Hasta el 22 de agosto de 2020, cuenta con 1250381 personas; por ende, es el noticiero en línea que cuenta con mayor público, dato que también concuerda con Siles González et al. (2018). Se caracteriza por recibir población de toda índole, aunque destaca la presencia de usuarios que utilizan lenguaje más vulgar. Este noticiero, al igual que Diario Extra,

\footnotetext{
${ }^{19}$ Según TN Relaciones (2020) a nivel nacional existen los siguientes periódicos: Diario Extra, Diario Oficial La Gaceta, El Financiero, El Heraldo, La Nación Digital, La Prensa Libre, La República, La Teja y Tico Times (English). No obstante, en lo que compete a medios nacioanales en internet están: A.M. Costa Rica (English) AMPrensa, Costa Rica News (English), CrHoy.com, Cyberprensa (English), Delfino, El Guardián, El Mundo, El País CR, El Periódico CR, Informa Tico, NCR Noticias Costa Rica, NoTiciero, Noti Costa Rica, Q Costa Rica (English), Tico Deporte y Fútbol en vivo Costa Rica. http://www.tnrelaciones.com/anexo/prensa_costarica/index.html.
} 
se caracteriza por publicar gran cantidad de noticias diarias (10 o más). Además, cuenta con una cantidad proporcional de reacciones en sus noticias.

- Seminario Universidad: Este es el periódico que menos seguidores registra, lo cual concuerda con los datos presentados por Siles González et al. (2018). Hasta el 22 de agosto de 2020 tiene un total de 153 674, muy por debajo de los otros tres noticieros analizados. Dentro de los datos a destacar, publican menos cantidad de noticias que los otros tres periódicos y son más selectivos que La Nación. En su perfil de entrada en internet indican: "Somos un espacio de opinión universitaria [...] Buscamos informar de manera crítica, formativa, independiente y pluralista, para la construcción de una sociedad más justa mediante un equipo de trabajo profesional comprometido". ${ }^{20}$

Tal y como se aprecia, es un periódico dirigido principalmente a la población universitaria. Solicitan comentarios críticos y profesionales. Durante la búsqueda de los datos de estudio se logró ver que, aunque sí existe participación en los comentarios, los usuarios suelen ser directos: emiten el mensaje tal cual es y no recurren con tanta frecuencia a recursos como el humor o la ironía. A nivel general, se observa muy buena ortografía, redacción y uso de lenguaje formal por parte de los usuarios.

\subsection{Procedimiento}

En cada periódico se rastrearon las noticias publicadas durante noviembre de 2019 . Se seleccionaron las que tuvieron mayor interacción por parte de los usuarios. Se hallaron temas vinculados con el Ministerio de Hacienda, la Universidad de Costa Rica (criticada por considerarse aliada de la corrupción del PAC) y la carroza de la UACA (relacionada con el concepto tradicional de familia).

Luego de tener el corpus de las noticias con mayores interacciones, ${ }^{21} \mathrm{se}$ leyeron los comentarios con el fin de seleccionar los que ofrecieran mayor contenido para un análisis pragmático. El cuerpo de estudio se categorizó a partir de la ironía y el humor. Asimismo, se determinó cuáles actos de habla son más frecuentes y con qué funciones. Los comentarios aparecen como información pública, por lo que en el análisis se utilizan los nombres de los usuarios tal y como se muestran en Facebook. No necesariamente coincidirán con el nombre verdadero, por tanto, se podrían considerar "nombres de pluma" o "seudónimos".

En la sección de análisis, se presentan los comentarios por noticiero, con los títulos y resúmenes correspondientes. Luego, se analizan los comentarios en el orden en que aparecen en Facebook; la información se copia y pega tal cual aparecía

\footnotetext{
${ }^{20} \mathrm{https}$ //semanariouniversidad.com/users/

${ }^{21}$ La investigación se realizó con 70 comentarios, provenientes de 49 ejemplos incluyendo secuencias discursivas. No obstante, se redujo a 29 comentarios y 16 ejemplos o casos incluyendo secuencias. Esto por cantidad de páginas para publicación en revista. Se decidió trabajar con 4 ejemplos por noticiero porque fue la máxima cantidad de muestras arrojadas por La Nación. Se escogieron los comentarios más relevantes. El análisis completo de los 70 comentarios se puede solicitar directamente a los autores de este trabajo a través de sus correos electrónicos.
} 
en esta red, es decir, "al pie de la letra", con todo y "emojis" (imágenes gráficas). ${ }^{22}$ Por último, se tomó como secuencia discursiva únicamente la respuesta directa al comentario de otro usuario (no a la noticia).

\section{Análisis y discusión}

En esta sección se presenta el análisis de los 29 comentarios publicados en Facebook. En primera instancia, se ofrecen algunas consideraciones generales sobre los comentarios encontrados y, luego, se expone el desglose por noticiero. A manera de resumen, la tabla 1 indica los títulos de las noticias consultadas para el corpus de estudio y la tabla 2, el desglose de comentarios por noticiero.

Tabla 1. Nombre del noticiero y título de las noticias analizadas.

\begin{tabular}{|l|l|}
\hline Noticiero & Título de la noticia \\
\hline Diario Extra & "Epsy Campbell sigue sintiéndose canciller" \\
\hline La Nación & $\begin{array}{l}\text { "Municipalidad de San José acepta participación de carroza de la UACA en Festival } \\
\text { de la Luz" }\end{array}$ \\
\hline CR Hoy & $\begin{array}{l}\text { Noticia 1: "PLN bombardea de mociones ley que suspendería salario a alcaldes que } \\
\text { buscan reelección" } \\
\text { Noticia 2: "Fotos: Así quedó edificio de ciencias sociales vandalizado por } \\
\text { universitarios" }\end{array}$ \\
\hline $\begin{array}{l}\text { Semanario } \\
\text { Universidad }\end{array}$ & $\begin{array}{l}\text { Noticia 1: "Sociedades de Aldesa suman millonarias deudas con Hacienda" } \\
\text { Noticia 2: "Alvarado expresa preocupación ante el aumento de 11,4\% del desempleo } \\
\text { durante el tercer trimestre" }\end{array}$ \\
\hline
\end{tabular}

Tabla 2. Cantidad de comentarios por noticiero (desglose por noticia) y cantidad de casos de cada acto de habla encontrados en los comentarios.

\begin{tabular}{|l|c|c|c|}
\hline \multicolumn{1}{|c|}{ Noticiero } & Cantidad de comentarios & Ironía & Humor \\
\hline Diario Extra & 9 & 6 & 3 \\
\hline La Nación & 6 & 5 & 1 \\
\hline CRHoy ${ }^{23}$ & $\begin{array}{c}\text { Noticia 1: 1 } \\
\text { Noticia 2: 7 5 [un mismo } \\
\text { usuario comenta 2 veces] }\end{array}$ & 6 & 4 \\
\hline $\begin{array}{l}\text { Semanario } \\
\text { Universidad }\end{array}$ & $\begin{array}{c}\text { Noticia 1: } 4 \\
\text { Noticia 2: } 2\end{array}$ & 4 & 2 \\
\hline
\end{tabular}

\subsection{Consideraciones generales}

Antes de presentar el detalle del análisis de los comentarios, es valioso ofrecer algunas consideraciones generales sobre los datos recolectados y la definición del corpus. En primer lugar, los periódicos publican diferente cantidad de noticias y reciben distinto número de comentarios, por lo que se seleccionaron por relevancia según los objetivos de este trabajo. Es decir, no se tomó una muestra aleatoria de cada periódico y, por esta razón, no se pueden establecer comparaciones entre

\footnotetext{
22 Basado en la metodología utilizada por Sampietro (2016).

${ }^{23} \mathrm{El}$ hecho de que haya 8 comentarios y 10 actos de habla se debe a que algunos comentarios presentan actos tanto de ironía como de humor, separados por cortes con signos de puntuación. Tal cual se apunta en el corpus, este fue el noticiero que, por medio de sus comentarios, más posibilidades de análisis arrojó.
} 
periódicos para determinar en cuál hay mayor o menor presencia de un determinado acto de habla.

En segundo lugar, cuando se realizó el análisis con el corpus completo (70 comentarios) hubo mayor cantidad de comentarios en Diario Extra y CRHoy, este último con la mayor cantidad de comentarios de todos, que en La Nación y Semanario Universidad, el cual ofreció la menor cantidad de comentarios (similar a Siles González et al. 2018). Sin embargo, se decidió trabajar con cuatro ejemplos por noticiero, dado que fue la máxima cantidad presentada por La Nación. Se seleccionaron los comentarios más relevantes según el análisis propuesto.

En general, se encuentran varias faltas ortográficas y de redacción (mayor cantidad en CRHoy y menos en Semanario Universidad) y abundante uso de elementos no verbales (emojis y reacciones). Como se indicó en la metodología, los comentarios se copiaron tal cual para preservar el mensaje original y no manipular los datos. ${ }^{24}$ No se extraen conclusiones del uso lingüístico de los usuarios, ya que este no es el objeto de estudio del presente trabajo.

Por último, cabe recordar que en el desarrollo de esta investigación se analizaron 70 comentarios en total. Sin embargo, a continuación se incluye solamente una muestra de cada noticiero para ilustrar el uso de los actos de habla en estudio, así como la variedad de recursos empleados (secuencias de comentariosrespuestas, recursos lingüísticos verbales y recursos lingüísticos no verbales).

\subsection{Análisis por noticiero}

En esta sección se presentan 29 comentarios incluidos en 16 ejemplos extraídos de cuatro noticieros costarricenses, así como el análisis del tipo de acto de habla y los recursos lingüísticos empleados. Para cada periódico, se indica el título de la noticia y un resumen para ofrecer el contexto necesario para la interpretación de los actos de habla. Se escogieron los cuatro mejores ejemplos por noticia a partir de los elementos más significativos para este trabajo. Cabe decir que cuando se habla de un ejemplo bajo la siguiente gráfica "[1]" se incluyen sus secuencias argumentativas, es decir, no solo un comentario, sino también sus respuestas.

\subsubsection{Diario Extra}

Los comentarios de este periódico provienen de una noticia relacionada con la molestia provocada por la presunta mala administración del dinero en el país. De ella, se extrajeron nueve comentarios para su análisis.

1) Título de la noticia 1: "Epsy Campbell sigue sintiéndose canciller".

Resumen: Esta noticia está relacionada con la corrupción de ciertos políticos que presuntamente utilizan recursos estatales para viajar. El ataque va destinado a Epsy Campbell, a quien se le reprocha que se aprovecha del dinero del Estado para seguir viajando a pesar de ya no ser canciller.

Análisis de los comentarios:

\footnotetext{
${ }^{24}$ Alternativamente, se podrían presentar capturas de pantalla, como en el caso de González (2020); sin embargo, para efectos del análisis lingüístico, se prefirió copiar los comentarios verbatim.
} 
Mo alt Keylin: "Los ticos somos vacas domesticadas te amamos. Bravooooo De lo mejor que ha podido tener nuestra amada Patria"

En la referencia [1] es importante observar la conjugación del verbo ser en presente de indicativo en la tercera persona plural, pues remite a una colectividad, cuyo fin es identificar a los costarricenses a partir de la metáfora "vacas domesticadas". Es decir, se compara a los ciudadanos con seres acríticos y sumisos. Existe una molestia, manifestada por el uso irónico de "te amamos", cuyo mensaje de fondo, por antífrasis es "te odiamos".

Luego, es importante el uso del "." [punto] como marca porque oxigena el mensaje para reforzarlo con el uso de "bravoooooo" [con seis "o" se intensifica] acompañado del indicador no lingüístico \& [mano saludando] utilizado normalmente para asuntos positivos. De nuevo, es importante la función que posee la marca de "." [punto] porque da espacio a la redacción de otro mensaje cuyo fin es reafirmar la molestia con el siguiente acto de habla irónico: "De lo mejor que ha podido tener nuestra amada Patria". En este caso, el uso de "mejor" y "amada" ironizan la intención de crítica, pues, contextualmente hablando, el daño que le siguen haciendo al país remite al detrimento de la patria y a la falta de amor hacia ella. Mediante implicatura, se propone que el trasfondo del mensaje ironizado conduce a un sentimiento de fuerte descontento hacia al presidente costarricense [domador de vacas], quien está muy lejos de ser lo mejor que tiene esta patria.

2) Nor Carb: "Que titular poco serio ..atizando odios sres. Sin importar el color politico del partido de turno. Es Vicepresidenta y cumples roles como tal".

Mario Bonilla: "Nor Carb jajaja jajaja jajaja Siervos menguados".

Jafeth Batista Mora: "Pase esas gafas PAClover por favor".

En cuanto al caso [2], contrario al primero que recurre a una respuesta del titular, se da una secuencia argumentativa a partir del comentario de Norb Carb quien defiende a la vicepresidenta costarricense. Al respecto, de manera burlesca, recibe 19 reacciones "me divierte" que se entienden mejor con el siguiente análisis de las respuestas recibidas. El usuario Mario Bonilla utiliza el acto de habla humorístico mediante "Siervos menguados", que, aparte de estar en mayúscula, como figura retórica, para personalizarlo y subir su tono, aparece acompañado del recurso humorístico "jajaja”, que según Schoentjes (2003) incrementa la intención del mensaje. Además, como impacto crítico, "Siervos menguados", se asocia con "vacas domesticas" (Mo alt Keylin) expuesto en el comentario [1]. Esto permite apreciar cómo los animales se convierten en figuras clave para agregarle una carga semántica humorística a los mensajes.

Desde esta óptica, es indudable el desdoblamiento, mediante humorización crítica, del himno patriótico al 15 de septiembre donde se dice "sepamos ser libres / no siervos menguados". En el trasfondo del mensaje, se indica que el tico no cumple con lo solicitado en un himno, cuyo motivo remite a una independencia todavía no conseguida a nivel ideológico en pleno siglo XXI. Por implicatura, se sugiere que los ticos no deben ser "siervos menguados" como lo piden los aparatos de poder, porque de lo contrario se defenderían los fraudes políticos, según 
pareciera que defiende Norb Carb y de allí el uso de los actos de habla para refugiar mensajes detrás de sus respuestas.

Asimismo, siguiendo con la secuencia argumentativa iniciada por el comentario de Nor Carb, Jafeth Batista Mora utiliza la ironía como cuestionamiento a la irracionalidad del ciudadano costarricense. Ante ello, cabe destacar el uso de "gafas PAClover". Las "gafas", instrumento que ayuda a mejorar la vista, se convierten en metáfora de una cultura ciega que no quiere ver, en noviembre de 2019, el trasfondo de sus problemas políticos. Por su parte, este acto de habla irónico también remite a una burla contra los seguidores fanáticos del PAC (Partido de Acción Ciudadana, actualmente en el poder). Por último, la solicitud se incrementa con el uso de un acto cortés, "por favor", que denota la necesidad de urgencia de un cambio político e ideológico en el pueblo costarricense.

3) Carla Borge: "Pero no entiendo la incomodidad si la organización la invitó con los gastos pagos y todo, que es la jodeera por Dios, de verdad que hay diputados que

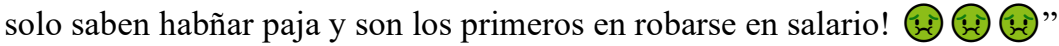

Manuel Esteban Azofeifa Fallas: "Carla Borge y a usted no la invitaron?"

Salas Carlos: "Carla Borge PERFECTA IGNORANTE"

Carla Borge: "Carloshumberto Salas Porras jajajajaj habló megamente.... que miedo!! Jajajajaja"

Óscar Murcia Bol: "Carla Borge mi abuela es virgen."

Alexander Madrigal Flores: "Carla Borge ahhh ahora todo es noticias falsas. 웅 으,"

En el caso [3], los comentarios se dan por secuencia argumentativa debido a la oposición de los usuarios contra lo escrito por Carla Borge. Azofeifa transmite un acto irónico reforzado a partir de un signo de pregunta, cuyo efecto o intención, se difiere, es generar mofa hacia Borge y, a la vez, considerarla cómplice de la corrupción del PAC (la usuaria ignoró el comentario, reforzado por 2 reacciones de "me divierte").

Enseguida, Borge recibió un comentario irónico de Salas, casi cayendo en el sarcasmo. ${ }^{25}$ A través de una antífrasis se le dice "perfecta ignorante", pues un ignorante no puede ser perfecto. Este mensaje, al ser entendido por su receptora Borge, se refuerza mediante secuencia argumentativa, pero ahora mediante el uso del humor y luego de la ironía. Ella, de manera humorística, utiliza la figura ficticia de "megamente" 26 como recurso para reírse de la "supuesta" inteligencia de Salas. Incluso, este acto de habla humorístico, tal cual lo defiende a nivel teórico Schoentjes (2003), se refuerza de manera a partir de risas duplicadas "jajajajaj" "jajajajaja”. Luego, ya no enmarcado en un acto de habla humorístico, sino irónico, dice: "que miedo" pues, por contexto se infiere que Borge no tiene miedo. Ella

\footnotetext{
${ }^{25}$ El sarcasmo, contrario a la ironía, siempre busca generar daño, ofender.

${ }^{26}$ Megamente, película de Pixar del 2010.
} 
utiliza la ironía como una herramienta provocativa para defenderse de quien intenta ofenderla y a la vez, de nuevo, mediante risas "Jajajajaja", duplica la provocación.

Los ataques contra Borge continúan. Primero, Murcia utiliza un acto de habla irónica, cuyo mensaje de trasfondo le comunica a Borge que es, básicamente, una ingenua (mi abuela es virgen); luego, Madrigal, utiliza la ironía para cuestionar la falta de criticidad de Borge mediante "ahhh ahora todo es noticias falsas". El uso de "ahhh" busca que el receptor, en este caso Borge, crea que Madrigal entró en razón y, por ende, apoya lo que dijo, lo cual se entiende que no es el caso. Por este mismo motivo, humoriza la ironía mediante el uso de 2 indicadores no lingüísticos [emojis risibles: (-) (-)]. Más que una crítica social, en este caso, existe un deseo de provocación para generar una disputa verbal. Por eso, la atacada se defiende, aunque ya no hace uso de ironía o humor (secuencia no incluida en [3] por situarse fuera del ámbito de este trabajo). Responde con total educación, criticidad y dominio de temas, hasta dejar a sus atacantes en silencio, con lo cual concluye la discusión.

4) Isaac Daniel: “Tranquilos.... es por tí, es por Costa Rica...”.

En el comentario [4] se presenta un acto de habla irónico generado mediante antífrasis, pero con un reforzamiento. Nuevamente, la ironía se utiliza como recurso contestatario. Se critica mediante una expresión que utilizó el PAC en su campaña política "Es por vos, es por Costa Rica" El choque de contrarios se refuerza aún más cuando se atiende a la función del sustantivo "Tranquilos...", puesto que, por implicatura, la intención del mensaje es decir que los costarricense no deben estar tranquilos, pues los han engañado con un discurso ficticio que decía querer ayudar a todos los ciudadanos, aunque, su gran mayoría han sido afectados.

\subsubsection{La Nación}

Para el análisis de datos de este periódico, se cuenta con una sola noticia, de la cual se lograron extraer cuatro comentarios para su análisis.

5) Título de la noticia: "Municipalidad de San José acepta participación de carroza de la UACA en Festival de la Luz"

Resumen: La municipalidad de San José aprobó la participación de la carroza de la UACA (Universidad Autónoma de Centro América) en el Festival de la Luz realizado en 2019. Dicha carroza alude al concepto tradicional de "familia", lo cual provocó muchas molestias en los costarricenses que buscan una definición más progresista del concepto. Entre los comentarios de molestia se encontró el argumento de que la carroza no es inclusiva, sino que discrimina al intentar imponer un único concepto de familia.

\section{Análisis de comentarios:}

Martha Navarro Obando: "Es curioso se molestan por una carroza que va a participar en algo tan hermoso como el festival de la Luz y que representa a la familia. $\mathrm{Y}$ el resto de nosotros tenemos que aceptar el desfile que realizan todos los años donde ofenden a los religiosos con sus trajes o caracterizando escenas sexuales, sin ninguna necesidad". 
Guadalupe Rodríguez: "Martha Navarro Obando y nosotros tenemos que aceptar las procesiones y disfraces que utilizan los religiosos caracterizando escenas violentas donde alguien ensangrentado va cargando una cruz y no nos ve quejándonos 0 "

En el caso [5] se presenta un fuerte caso de acto de habla irónico contra un discurso tradicional religioso. Este se genera a partir de la secuencia argumentativa creada por medio de una disputa verbal. Por un lado, Navarro muestra su descontento con las críticas hechas por quienes están en contra de la carroza de la UACA sobre el concepto tradicional de familia. De manera irónica dice no entender cómo existen personas que se molestan por la carroza si quienes están a favor tienen que "aguantarse" sus participaciones liberales en distintos eventos. Por otro lado, aparte de recibir nueve reacciones de "me divierte" [indicador no lingüístico] cuyo significado remite a la reacción humorística que ha generado su mensaje, Rodríguez responde de manera irónica diciendo que no solo los "religiosos" deben "aguantarse" las vestimentas o comportamientos de los "liberales", pues ellos [no religiosos] también deben "soportarse" las vestimentas y escenas violentas de los creyentes. Hay una desacralización del discurso religioso de poder, bastante arraigado en Costa Rica.

Además, el mensaje se refuerza a través de un indicador no lingüístico [emoji “- "] cuyo fin es mostrar más a profundidad lo molesta que está Rodríguez, razón por la cual recibe 9 reacciones de "me divierte" [indicador no lingüístico]. Según se interpreta, a los usuarios les divirtió mucho ver cómo Rodríguez logró aferrarse del mismo argumento de Navarro para atacarla de manera indirecta, inteligente y muy creativa por medio de un acto de habla irónico.

6) Henry Pizarro: "Se terminó el Festival de la luz para mi familia y Ojalá muchas familias se manifiesten no asistiendo ni observando la transmisión x ningún canal, hagamonos sentir familias de valores"

Marián Torres: "uy no o sea ya lo cancelaron xq tu familia no va!!".

Lucía Rodríguez: “Amor a la vida??”

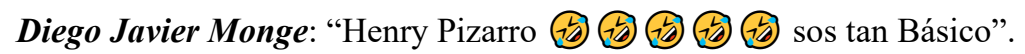

En relación con el caso [6] se dan dos casos de ironía y uno de humor. Esto se genera por medio de una secuencia argumentativa debido a la molestia generada por el comentario de Henry Pizarro, quien defiende la ideología de la familia tradicional. Primero, a manera de respuesta, Rodríguez utiliza un acto de habla irónico cuyo trasfondo comunica que a nadie le interesa que la familia de Pizarro no asista al Festival de la Luz; es decir, el fin es hacer mofa de manera indirecta y con ello generar una especie de placer en el emisor. El uso de "uy no", que remite a una sorpresa o indignación, y los signos de admiración refuerzan el tono del enunciado.

Acto seguido, Rodríguez utiliza los signos de interrogación para intensificar su acto de habla irónico. Dichos signos de pregunta cumplen la función de cuestionar el comentario de Henry Pizarro, sin embargo, el mensaje no recibe respuesta y, por ende, la intención no sobrecarga su objetivo: cuestionar las 
ideologías de la familia tradicional. ${ }^{27}$ En cuanto al aporte de Monge, se presenta un acto de habla humorístico, cuyo fin es ofender a Pizarro. Cabe decir que la burla se

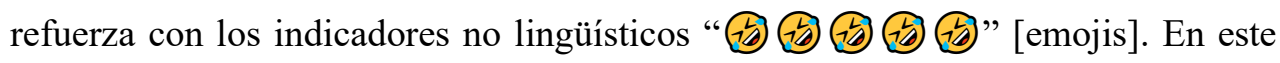
caso, la palabra básico se podría decodificar, de manera ofensiva, como "ignorante", "bruto".

7) Alejo Hernández: "Ya se! Hagamos una carroza toda blanca y cada uno se imagina lo que quiera! Un feto, Juan Gabriel, la 30 de la liga, una birra gigante, no se lo que lo llene como persona! Además así nadie se ofende! Ni lgtb ni aleluyos :)".

En el caso [7] se da un acto de habla irónico, cuyo contenido es quizás de los más fuertes y cargados a nivel social, así como a nivel de mofa. En este enunciado, aparte del uso de "Ya se" para mostrarse sabio, e incluso, con cierta prepotencia, se utiliza un signo de admiración para aumentar el tono de la expresión. Por su lado, hay referencia a diferentes temas que han generado brechas ideológicas en el país, entre ello un feto [luchas feministas], el ya fallecido cantante mexicano Juan Gabriel [en tanto ícono para las personas homosexuales], el campeonato 30 de la liga [pugna contra su equipo adversario: Saprissa], una birra gigante [factor dionisiaco, el placer, el éxtasis], las poblaciones "lgtb" [comunidad lesbiana, gay, trans y bi] y los "aleluyos" [en referencia a los fanáticos religiosos]. En este caso, dicha expresión intensifica su significado al dirigirse a Fabricio Alvarado, político y aspirante a la presidencia, y a sus seguidores, quienes apoyan el concepto tradicional de familia.

Cabe destacar que, si el mensaje de Hernández se leyera hasta la palabra "persona", podría pensarse que el usuario utiliza la ironía para criticar fuertemente a quienes defienden al extremo la ideología de familia tradicional y, por ende, se pensaría que él apoya las diversidades. Sin embargo, luego del uso del adverbio "además" se denota su molestia contra los religiosos y los homosexuales por igual, quienes, a su parecer, se ofenden por todo y pasan metidos en conflictos. Su fastidio se enfatiza por medio del indicador no lingüístico “:)", con uso humorístico en este contexto.

8) Álvaro Bermúdez: "Muy linda la carroza de death stranding"

En el caso [8] se encuentra un acto de habla irónica cuya función es la burla, pues, bajo interpretación, contrario a ver la carroza "muy linda", la considera utópica, fantástica y poco cercana a la realidad, debido a que en el juego Death Stranding se propone un modelo de vida asexual y los bebés son clonados, no concebidos. Además, el uso del adverbio "muy", acompañado del adjetivo "linda" intensifica la carga burlesca del enunciado.

\subsubsection{CRHOY}

En cuanto a este noticiero, se cuenta con seis comentarios recogidos de las dos noticias que mostraron mayor reacción en comparación con el resto.

\footnotetext{
${ }^{27}$ Todo acto de habla se intensifica, primero, por medio del entendimiento del receptor, pues si no se entiende, no se da el acto de habla, principalmente la ironía, y segundo, mediante la respuesta del receptor, que pasa a cumplir el rol de emisor. No obstante, esta respuesta debe venir cargada con un acto de habla irónico.
} 
9) Título de la noticia 1: "PLN bombardea de mociones ley que suspendería salario a alcaldes que buscan reelección"

Resumen: La noticia trata sobre los salarios de los políticos que quieren ser reelectos y la propuesta del PLN (Partido de Liberación Nacional). Se registraron ocho comentarios.

\section{Análisis de comentarios:}

Manu Peña: "Que PLN no paso llorando en la asamblea por la corrupción y los mas

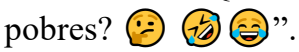

En el caso [9] se genera un acto de habla humorístico reforzado por el uso de

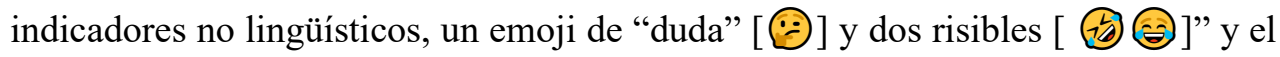
uso del signo de puntuación de cierre. Cabe destacar el lenguaje figurativo, entre ello, "llorar" que remite a la queja constante y la pérdida de tiempo, en vez de aprovecharlo combatiendo la corrupción y luchando por los pobres.

Por su lado, el trasfondo de este acto de habla humorístico, más que un simple placer detrás de la risa, desde nuestra interpretación, remite a la crítica contra la labor del Partido Liberación Nacional (PLN) anterior al PAC [entró a regir en 2014, luego del gobierno de Laura Chinchilla]. El comentario busca que los ciudadanos costarricenses tomen conciencia y dejen de votar por este partido. La usuaria sabe la respuesta a su pregunta.

10) Título de la noticia 2: "Fotos: Así quedó edificio de ciencias sociales vandalizado por universitarios"

Resumen: La nota gira en torno a la toma de uno de los edificios de Ciencias Sociales de la Universidad de Costa Rica, este fue rayado por los estudiantes durante una huelga. Cabe destacar que, de todo el corpus seleccionado para el análisis, esta es la noticia que más comentarios irónicos y humorísticos desató.

\section{Análisis de comentarios:}

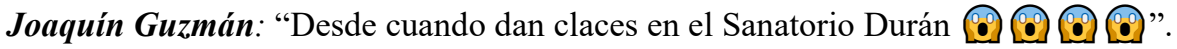

Andrés Víquez: Desde que la mayoría de la población, la "sana" está constituida por puros sometidos, siervos menguados que le chupan los pies al gobierno"

Rodrigo Arce Campos: "Andrés Víquez Pero si uds votaron pac y les hicieron campaña, que mas Siervo y menguado que eso?”.

Joaquín Guzmán: Andrés Víquez ahhh disculpe, muy bonito quedaron esas paredes pfff".

Joaquín Guzmán: “Andrés Víquez di bañazo, se quedo sin argumentos la princesita 우웅ㅇㅇ.

En el caso [10] se da un acto irónico reforzado por la interrogante hecha por el usuario "Desde cuando" y por tres indicadores no lingüísticos, los emoticones de

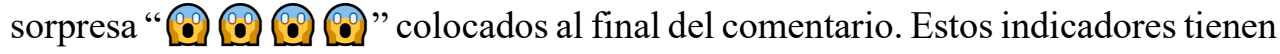
una función muy importante, porque, a modo de estrategia, provocan una 
construcción lúdica en el enunciado. A su vez, a modo de juego, o ficción, este acto le permite al emisor presentarse como alguien que desconoce la situación de la que habla. Incluso, si no se conociera el contexto, se creería que el emisor es iluso, especialmente, si no se tuviera referencia sobre el Sanatorio Durán, centro de salud donde se albergaban y trataban los pacientes con tuberculosis, famoso por las numerosas impresiones que llenan sus paredes y por la popular creencia de estar embrujado.

En un sentido irónico, el usuario altera el lugar de los hechos, porque no en el Sanatorio Durán donde se imparten las lecciones: en realidad se estaban dando en la Universidad de Costa Rica. Sin duda, el emisor se hace "pasar por tonto" y esto le permite comparar a la Universidad de Costa Rica con un sitio donde aparentemente asustan. Solo que, desde la interpretación de este comentario, no asuntan los fantasmas, sino los actos vandálicos de ciertas personas. Su acto de habla irónico se entona con burla, evidenciada gracias a la presencia de un indicador no lingüístico de interés: diez personas reaccionaron con "me divierte" a su comentario.

Enseguida, Víquez utiliza la ironía y el humor en su respuesta, con una función de cuestionamiento y crítica social. Para ello, utiliza tanto un lenguaje figurativo como coloquial. En un primer caso, se construye la duda a partir del uso de comilla [la "sana"] lo que remite a la deconstrucción del imaginario nacionalista y da paso a la posibilidad de imaginarse la identidad costarricense desde una descomposición. Segundo, tal cual se había presentado en el caso [2] de Mario Bonilla, se genera un acto de habla humorístico a partir de la referencia "Siervo menguado", cuyo fin es generar mofa sobre los costarricenses acríticos que se dejan manipular sin oposición alguna. Este tema se repite a lo largo del corpus y se convierte en un tópico de denuncia contrahegemónico y antinacionalista. Tercero, en un tono coloquial, critica a los "chupa medias del gobierno", lo que remite a un cuestionamiento contra aquellas personas que se dejan llevar por las conveniencias en lugar de apostar por el pensamiento crítico como herramienta constructora de cambio.

No obstante, a manera de secuencia argumentativa, se muestra un caso de ironía con una función burlesca y de diversión en la respuesta de Arce a Víquez, a la vez enlazado con el primer comentario de Guzmán. Su comentario, al igual que el de Guzmán, recibió, a modo de indicadores no lingüísticos, diez reacciones de "me divierte". Además, la intención del comentario de Arce se refuerza a partir del signo de interrogación "?", cuya respuesta el emisor supone. Por su lado, este usuario utiliza la figura del "Siervo menguado" como referente humorístico de crítica. Se comprueba la constancia de esta figura como tópico de incomodidad con ciertos comportamientos sociales de sumisión y acriticidad.

Enseguida, el mismo usuario que inició "el debate", Guzmán, continúa la secuencia argumentativa. Utiliza un acto de habla irónico generado mediante lo que tradicionalmente se conoce como antífrasis. Por el contexto de la conversación se interpreta que ya no importa tanto la manifestación social, sino satisfacer sus deseos de triunfo al encontrarse en una brecha con Andrés Víquez. El tono de su enunciado remite a una persona molesta, evidenciado por el uso del "pfff", cuya función remite al desmérito del pensamiento de su adversario. 
Al no haber respuesta del usuario interpelado (Víquez), Guzmán recurre al uso de un acto de habla humorístico, cuyo fin es insultar indirectamente a Víquez y con ello intentar provocarlo para que se sigan dando las secuencias argumentativas. Se vislumbra un deseo narcisista de sentirse triunfante, lo cual lo hace caer en un lenguaje vulgar. Además, emplea el diminuto "ita" con el afán de incrementar la carga de ofensa y burla, misma que se intensifica por medio de tres emojis risibles

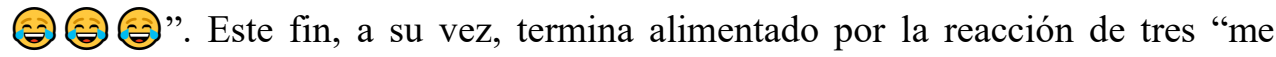
encanta" por parte de otros usuarios. De este modo, se da cierre al acto comunicativo, que, como se dijo al inicio, se caracteriza por ser el más cargado de secuencias argumentativas en esta investigación.

11) Yendry Flores: "Mira los hijos de Charlie son bien creativos con sus manitos...".

Max Eduardo Bellido: "Muy lindas le quedaron decoradas las paredes (-) (a)

En el caso [11] se da un acto irónico cuya función es criticar el comportamiento de algunas personas a quienes se les asocia con Carlos Alvarado, actual presidente en Costa Rica. Existe un desdoblamiento discursivo, generado en "son muy creativos", puesto que, por el contexto brindado por el resto de los comentarios, existe una molestia rotunda de los usuarios respecto a las paredes rayadas en uno de los edificios de la Facultad de Ciencias Sociales de la UCR.

Se cuestiona la nueva manera de hacer "arte" por parte de algunas personas. Esta creatividad a la que se apela es incómoda y no es para nada gustosa. Por esta razón, la crítica de Flores se refuerza mediante el acto burlesco "hijos de Charlie". Se considera que este tipo de actitudes son apoyadas por el presidente de Costa Rica. A su vez, se construye una imagen futurista del país bastante desesperanzadora, llena de caos, brechas y rebeldías sociales. Cabe decir que esta incomodidad por parte de la usuaria se refuerza mediante el uso de los puntos suspensivos [...], puesto que dejan abierto el mensaje a la reflexión crítica, que es justamente lo que busca la ironía, principalmente, en el corpus analizado.

En la misma referencia [11], Bellido utiliza un acto de habla humorístico para cuestionar los actos cometidos. Se observa una intensificación semántica por medio del adverbio "muy" acompañados del adjetivo "lindas", lo cual pone en duda la estética de las paredes luego de que las rayaran. Asimismo, este tono de duda y

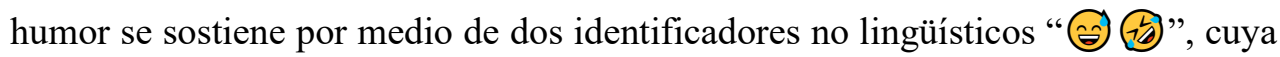
energía remite a una satisfacción desde el mismo acto más como descarga emotiva que como crítica social. El interés social, aunque está presente, no es tan pronunciado como en otros casos ya expuestos.

12) Óscar Muñoz: "Con Fabri las cosas estarían mejor 워”.

En el caso [12] se presenta un acto irónico con una función crítica y burlesca desde lo creativo. Primero, cabe decir que el comentario posee siete reacciones "me divierte", lo cual evidencia su objetivo burlesco y permite dicha interpretación. Sin duda, estas reacciones o indicadores no lingüísticos acrecientan la intención de trasfondo del enunciado. Segundo, al decir que con Fabricio Alvarado (el candidato que perdió en las últimas elecciones ante el actual presidente, Carlos Alvarado) se estaría mejor se pone en entredicho la realidad de la situación, provocando un tono 
de burla contra quienes así lo consideran. Por el contexto, se interpreta que, si hubiera quedado Alvarado, el país estaría peor, por medio del uso de contrarios. Tal dato se sustenta del indicador no lingüístico "구으. [emoticón que remite a un estado de tristeza] para darle, de manera creativa, un mayor realce a la intención de incomodidad sociopolítica.

\subsubsection{Seminario Universidad}

De la página en Facebook de este noticiario, se escogieron tres noticias.

13) Título de la noticia 1: "Sociedades de Aldesa suman millonarias deudas con Hacienda"

Resumen: Se señala que Aldesa es la sociedad que más dinero le debe al Ministerio de Hacienda costarricense por temas de impuestos evadidos.

\section{Análisis de comentarios:}

Grace Madrigal: "Y la esposa del dueño de Aldesa el presidente la premió con un puesto en el exterior".

Guillermo Rodríguez: "Mientras tanto, dónde estaban los inspectores de tributación que se encargan de detectar esas deudas. Usted sabe dónde estaban ¿?"

Grace Madrigal: "Guillermo Rodriguez si yo sé dónde estaban: haciendo cacería de brujas a los medianos y pequeños empresarios".

En el caso [13] existe un acto de habla irónico a manera de crítica a la corrupción, evidenciado mediante el verbo "premiar" utilizado por Madrigal, pues se otorgan puestos en el extranjero a personas que no lo merecen. Seguidamente, Rodríguez utiliza los signos de interrogación y el punto y seguido, no solo para intensificar la carga irónica en su comentario, sino también para dar paso a una secuencia argumentativa finalizada por Grace Madrigal. El empleo del pronombre personal "usted", apelando a la interlocutora, manifiesta la molestia contra la corrupción ejercida por el Ministerio de Hacienda en Costa Rica.

No obstante, al invitar a una secuencia argumentativa, la respuesta se genera en manos de Grace Madrigal, quien contesta de manera irónica y creativa, lo cual le permite reforzar de manera dinámica este acto de habla. Ella utiliza lo fantástico para expresar su descontento hacia los funcionarios del Ministerio de Hacienda, quienes, aparentemente, no se preocupan por investigar a quienes más dinero tienen [grandes empresarios], sino todo lo contrario [obstruyendo el camino de los pobres].

14) Olman Castro: "Y donde está gloria Navas, ah, se me olvidò que ella es la esposa del abogado de Los estafadores de Aldesa"

En el caso [14] se presenta un acto irónico reforzado a partir no solo de una interrogante, sino también mediante la antífrasis apreciada en "ah, se me olvidò". Seguido de ello, lanza una interrogante que él mismo acentúa tras decir que se le había olvidado un dato, aunque esto no fuese así: simplemente ironiza más su comentario para aumentar la crítica contra Gloria Navas, a quien además se le cuestiona por ser esposa "del abogado de Los estafadores de Aldesa". Así, se 
intensifica la carga crítica del enunciado, dirigiéndose a varios estafadores, y no solo a uno.

15) Título de la noticia 2: "Alvarado expresa preocupación ante el aumento de 11,4\% del desempleo durante el tercer trimestre"

16) Resumen: Se indica que el presidente costarricense está preocupado por el aumento del desempleo en el país. Esta nota obtuvo la mayor cantidad de reacciones en Semanario Universidad, no solo a nivel de ironía, sino en términos generales.

17) Análisis de comentarios:

18) Flora Ovares: 28 "El Presidente ha ido a otros países a buscar inversiones, ha tratado que la gente se prepare, a mejorado infraestructura y condiciones. Han llegado empresas y se han abierto centros de trabajo- No ha sido suficiente pero es injusto decir que no está trabajando en solucionar el desempleo".

19) Jefri Rodríguez: "perdón señora, pero se ganó merecidamente el 유".

20) Cristian CM:

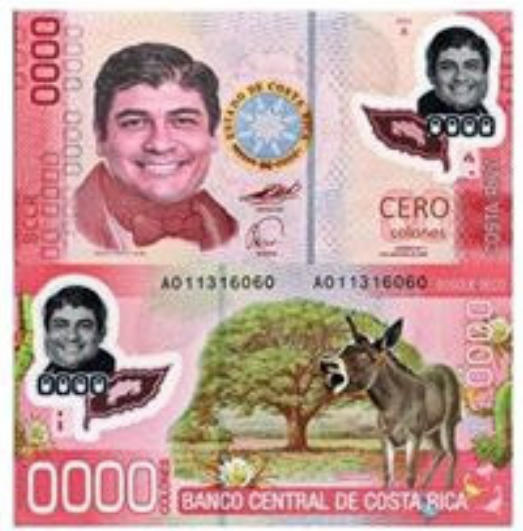

En el caso [15] se dan actos de humor. Incluso, tal cual se expondrá, de humor gráfico, todos ellos en tono de burla contra el pensamiento de Flora Ovares. En cuanto al comentario de Rodríguez su fin no es pedir "perdón", simplemente lo escribe como una manera cortés, "amable" o "humorística", de burlarse. Este acto carnavalesco se refuerza enseguida con el uso del indicador no lingüístico ";)". También, como parte de la secuencia argumentativa, aparece el mensaje de Cristian $\boldsymbol{C M}$, quien utiliza una imagen para dar paso al humor gráfico, que tiene dos funciones: aparte de generar risa, busca emitir una crítica humorística contra el presidente Alvarado, quien se convierte en meme (concepto manifestado por un medio virtual, en este caso por una imagen). Véase nuevamente el uso de un animal como recurso humorístico, en este caso ya no una vaca o un siervo, sino un asno o burro. Este indicador (meme) forma parte de los signos culturales que, según Lotman (2000), conforman las imágenes gráficas.

\footnotetext{
${ }^{28}$ Cabe decir que no es Flora Ovares, crítica y académica costarricense. Se hace la aclaración porque se pueden dar las confusiones. Aunque, las faltas de ortografía y cometidos sintácticos en el enunciado hablan por sí solos.
} 
21) Carlos Luna Tortós: "pero según él vamos por buena ruta!!!”

En el caso [16], que es el último aquí expuesto, se genera un acto irónico con un lenguaje figurativo. Detrás de lo dicho se interpreta otro mensaje: los costarricenses no son tontos y saben cuando la situación no está bien. La ruta es metáfora del camino que construyen los arquitectos del país desde la Asamblea Legislativa. A su vez, por medio de la conjugación del verbo "ir", en primera persona plural del presente de indicativo "vamos", se remite a la existencia de una colectividad social que acrecienta la carga del acto de habla, la cual se ve aumentada por medio del adjetivo "buena". Por último, la ironía alcanza el clímax mediante el uso de tres signos de exclamación, que denotan la inconformidad total por parte del usuario, quien, por medio de la ironía, comunica la verdadera intención de denuncia en su mensaje.

\section{Conclusiones}

Entre el acto de habla irónico y el humorístico, el primero de ellos es el más utilizado por los usuarios. De los 29 comentarios analizados, 21 veces se utilizó el acto de habla irónico y 10 el acto de habla humorístico. A su vez, se descubrió que en las secuencias argumentativas los usuarios tienden a utilizar los indicadores referidos por Muecke (1978) y Schoentjes (2003) (citados por Alvarado Ortega, 2006; Sal Paz, 2016 y Sampietro, 2016), tales como las reacciones de "me divierte", los signos de pregunta, los puntos suspensivos, las oraciones dubitativas y los emojis.

Por otro lado, el análisis crítico de interpretación pragmática de los comentarios de los usuarios permitió inferir que las reacciones a los temas políticos, contrario al trabajo de Siles González et al. (2018), denotan una sociedad costarricense, en noviembre de 2019, bastante molesta con su gobierno. Salvo algunos casos en que la intención es el humor por el humor, la mayoría de actos de humor y, principalmente, ironía se emplean como expresión de ira o descontento mediante comentarios de noticias publicadas en Facebook. Además, en la mayoría de los casos, se utilizan indicadores (lingüísticos y no lingüísticos) para reforzar las intenciones de ataque o catarsis. También, se encontraron casos de humor cuya función es la protesta o denuncia.

Por último, cabe destacar que parte de los hallazgos de este artículo permiten dar a conocer dos datos de interés tanto para este estudio como para futuras investigaciones. Primero, es importante destacar que, según las muestras, se lograron apreciar diversidad de funciones y modos de construir, a través de diferentes factores pragmáticos, actos de habla irónicos y humorísticos que se refuerzan mediante secuencias argumentativas, reforzados por indicadores y marcas lingüísticas y no lingüísticas. Segundo, por medio de las implicaturas extraídas de los comentarios, los usuarios consideran que Costa Rica no es un paraíso del Edén, sitio donde, según el imaginario, no existe la violencia y abunda la paz. El análisis pragmático de los comentarios utilizados como muestra rompe con el mito de la arcadia tropical, arrastrado durante años.

Se aprecia gran cantidad de comentarios (tanto en la muestra de 29 comentarios utilizados para este artículo como la completa, conformada por 70 comentarios) de usuarios molestos, quienes maquillan (y, con ello, exaltan) su enojo haciendo uso, mayormente, del acto de habla irónico. Este acto de habla, según los 
datos obtenidos, funciona como conducto para expulsar las cargas emotivas que los usuarios prefieren no manifestar abiertamente: en el presente caso, la necesidad de expresar, en noviembre de 2019, sus profundas molestias con el gobierno del PAC. Esto podría verse como un factor positivo o negativo según el ángulo del que se mire. Al menos, desde el paradigma de este trabajo, se interpreta como algo positivo, porque hay usuarios intentando construir episteme y reconstruyendo imaginarios por medio de sus actos de habla.

\section{Limitaciones y futuras investigaciones}

Una de las principales limitaciones encontradas a la hora de recopilar el corpus fue la disparidad en cuanto al número de noticias publicadas por noticiero y la cifra de comentarios publicados como reacción a ellas. Esta discrepancia impidió realizar una comparación por periódicos, pues no se contó con muestras equivalentes que permitieran identificar las diferencias en los comportamientos de los seguidores de cada noticiero. En un futuro trabajo, podría diseñarse un proceso de recolección de muestra que permita comparar el uso de estos actos de habla de los diferentes usuarios, con el fin de hallar diferencias entre los públicos de cada noticiero.

Por otra parte, la selección de la muestra tampoco permitió establecer una comparación de los porcentajes de uso de los actos de habla según el sexo del usuario, ya que la muestra seleccionada no era representativa, sino ilustrativa. Un posible acercamiento a este problema sería hacer un conteo de todos los comentarios de una noticia para cuantificar la participación por sexo y, dentro de esa muestra, determinar el porcentaje de uso del la ironía y el humor. No obstante, el enfoque del presente trabajo, al ser cualitativo, no se prestaba para este tipo de análisis.

Finalmente, se escogieron noticias de temas políticos tras considerarse que generarían un tipo de respuestas que mostrara el uso de los actos de habla analizados $\mathrm{y}$, por consiguiente, una respectiva posición social. Sin embargo, se podría establecer una comparación con los comentarios publicados en respuesta a otro tipo de noticias, con el fin de evaluar si existe alguna diferencia en la cantidad o cualidad de uso de estos actos de habla o bien, verificar si la presente hipótesis -las noticias sobre política generan una mayor reacción, especialmente de los actos de habla de humor e ironía por su función de denuncia- sigue siendo válida.

\section{Referencias}

1. Cabo Isasi, A., y García Juanatey, A. (2016). El discurso del odio en las redes sociales: Un estado de la cuestión. Disponible en: https://ajuntament.barcelona.cat/bcnvsodi/wpcontent/uploads/2017/02/Informe_discurso-del-odio_ES.pdf

2. Caro Lopera, M. Á., Camargo Martínez, Z. y Uribe Álvarez, G. (2018). La ironía revisitada en sus dimensiones pragmáticas, comprensivas, discursivas y didácticas. Lenguaje, 46(1), pp. 95-126. Disponible en: http://brutus.facol.com/plataforma/assets/uploads/base/publicados/9c26ea38eb94d 592015018520f893f33.pdf. DOI: https://doi.org/10.25100/lenguaje.v46i1.6198

3. Casado Muñoz, M. I. (2017). El Humor deslde las Ciencias Sociales. El humor como herramienta de resistencia en movimientos sociales. El caso del 15M. Periferia, 22(1). Disponible en: https://ddd.uab.cat/pub/periferia/periferia_a2017v22n1/periferia_a2017v22n1p51.pdf . DOI: https://doi.org/10.5565/rev/periferia.513

4. Cautín-Epifani, V. (2015). Poder virtual y formas de tratamiento en el discurso mediado por computadora: Exploración en una red comunicativa virtual. Forma y 
Función, 28(1), pp. 55-78. DOI: https://doi.org/10.15446/fyf.v28n1.51971. DOI: https://doi.org/10.15446/fyf.v28n1.51971

5. García Gómez, T. y Martínez Rodríguez, J. B. (2015). Redes sociales y dispositivos móviles en la comunicación de los estudiantes de educación secundaria. Profesorado. Revista de Curriculum y Formación de Profesorado, 19(3), pp. 306324. Disponible en: https://www.redalyc.org/pdf/567/56743410021.pdf

6. González Campos, G. (2020). Representaciones discursivas de lo indígena en Costa Rica: Un análisis a través de la red social Facebook. Reflexiones, 99(2), 27-42. DOI: https://doi.org/10.15517/rr.v99i2.39040

7. Lotman, I. M. (2000). La semiosfera III: Semiótica de las artes y la cultura. Barcelona: Siglo Veintiuno de España.

8. Ridao Rodrigo, S. (2020). Actos de habla expresivos en la red social Facebook. Onomázein. Revista de lingüistica, filología y traducción, 47, pp. 225-239. DOI: https://doi.org/10.7764/onomazein.47.10

9. Ruiz Gurillo, L. (2010). Las 'marcas discursivas' de la ironía. En Cifuentes, J. L., Gómez, A., Lillo A., Mateo, J. y Yus, F. (eds.): Los caminos de la lengua. Estudios en homenaje a Enrique Alcaraz Varó (pp. 1-9). Alicante: Servicio de Publicaciones de la Universidad de Alicante. Disponible en: https://core.ac.uk/download/pdf/16374507.pdf

10. Ruiz Gurillo, L. (2019). El humor como hecho pragmático en español. Revista de investigación lingüística, 22, pp. 1831-9198. DOI: https://doi.org/10.6018/ril.381161

11. Ruiz Gurillo, L. (2014). Infiriendo el humor. Un modelo de análisis para el español. Círculo de linguística aplicada a la comunicación, 59, pp. 1481-9162. DOI: https://doi.org/10.5209/rev_CLAC.2014.v59.46712

12. Sal Paz, J. C. (2016). El comentario digital como género discursivo periodístico. Análisis de La Gaceta de Tucumán. Aposta. Revista de Ciencias Sociales, 69, pp. 1581-9216. Disponible en: https://www.redalyc.org/jatsRepo/4959/495952431007/index.html

13. Sampietro, A. (2016). Emoticonos y emojis: Análisis de su historia, difusión y uso en la comunicación digital actual. Tesis doctoral. València: Universitat de València. Disponible en: https://core.ac.uk/download/pdf/71058571.pdf

14. Sánchez Molina, A. C. (2002). Caricatura y prensa nacional (1. ed). Costa Rica: EUNA.

15. Siles González, I., Campos Acuña, P. y Segura Castillo, A. (2018). Sitios costarricenses de noticias en Facebook: ¿qué "likean", comentan y comparten sus usuarios? Revista de Ciencias Sociales, 160, pp. 371-9-55. DOI: https://doi.org/10.15517/rcs.v0i160.34806

16. Vargas Franco, A. (2016). Redes sociales, literacidad e identidad(es): El caso de Facebook. Colombian Applied Linguistics Journal, 18(1), pp. 111-924. DOI: https://doi.org/10.14483/calj.v18n1.9415

17. Villegas Uribe, C. A. (2007). El aporte de Ana María Vigara Tauste al nuevo paradigma de la caricatura. Semiótica, caricatografía y narrativa vital. Espéculo. Revista de estudios literarios. Disponible. en: https://biblioteca.org.ar/libros/150915.pdf

18. Yus, F. (2014). El discurso de las identidades en línea: El caso de Facebook. Discurso \& Sociedad, 8(3), pp. 3981-9426. Disponible en: http://rua.ua.es/dspace/handle/10045/45668
ANEXO
Páginas de Facebook consultadas:
19. https://www.facebook.com/crhoy.comnoticias/posts/3374725952569748
20. https://www.facebook.com/pg/crhoy.comnoticias/posts/?ref=page_internal
21. https://www.facebook.com/lanacioncr/posts/10162764918090051
22. https://www.facebook.com/crhoy.comnoticias/posts/3375019979207012
23. https://www.facebook.com/pg/crhoy.comnoticias/posts/?ref=page_internal 
$\operatorname{ASI}(\mathrm{E} \quad$ tep

24. https://www.crhoy.com/nacionales/pln-bombardea-de-mociones-ley-quesuspenderia-salario-a-alcaldes-que-buscan-

reeleccion/?fbclid=IwAROfdcaFu1ObHtrcDYoO3bvPVGOAq2_GMa7VwRObORxycEbCjR6bn-YOUA

25. https://www.facebook.com/search/top/?q=\%F0\%9F\%9A\%A8\%20\%23ATENCI\%C3\%9 3N\%20\%F0\%9F\%9A\%A8\%20\%7C\%20Campbell\%20se\%20fue\%20para\%20Kenia\%20y \%20la\%20Presidencia\%20no\%20comunic\%C3\%B3\%20nada\%20a\%20los\%20medios $\% 20 \mathrm{de} \% 20$ comunicaci\%C3\%B3n\&epa=SEARCH_BOX

26. https://www.facebook.com/diarioextra/posts/3048469541847210

27. https://www.facebook.com/semanariou/posts/3130598790343364

28. https://www.facebook.com/semanariou/posts/3113242448745665 